\title{
Ecological and axiological reflection of the concept of sustainable develop- ment as a basis for the health-preserving competence of a physical education teacher
}

\author{
Mykola B. Yevtuch ${ }^{1}$, Vasyl M. Fedorets ${ }^{2, *}$, Oksana V. Klochko ${ }^{3, * *}$, Nina P. Kravets ${ }^{4}$, and Tetiana R. Branitska ${ }^{2}$ \\ ${ }^{1}$ Institute of Pedagogy of the National Academy of Educational Sciences of Ukraine, 52-D Sichovykl Striltsiv Str., Kyiv, 04053, Ukraine \\ ${ }^{2}$ Department of Psychological and Pedagogical Education and Social Sciences, Public higher educational establishment "Vinnytsia \\ academy of continuing education", 13 Hrushevskoho Str., Vinnytsia, 21000, Ukraine \\ ${ }^{3}$ Department of Mathematics and Informatics, Vinnytsia Mykhailo Kotsiubynskyi State Pedagogical University, 32 Ostrozkoho Str., \\ Vinnytsia, 21001, Ukraine \\ ${ }^{4}$ Department of Psychocorrection Pedagogy, National Pedagogical Dragomanov University, 9 Pyrohova Str., Kyiv, 01601, Ukraine
}

\begin{abstract}
The article on the basis of the ecological value of reflection the concept of sustainable development and Hellenistic concepts is conceptual and methodological improvement of health saving competence of Physical Education teachers in the conditions of post-graduate education. There are presented methodological ways of greening of health and fitness technologies and identified opportunities for ecologically oriented their use by the teacher. Based on ecophilic interpretation of Hellenistic ideas are developed methodological concepts "Tellusantropo convergence" of the "Arete of the earth", "Tellusantropo harmonization", "Astoria of the Earth", "Tellusantropo reflection". Cultural, educational and technological sense of these concepts is existential axiological and ecophilic-oriented representation and interpretation the idea of sustainable development with the aim of using them as a Physical Education teacher in the educational health saving and fitness technologies and practices. In order to form a value relation to the Earth, to develop the "Arete of the Earth" and to unveil the "Existential of the Earth", we used the value-oriented reflexive technique of the "Epistrophe of the Earth". The method of "Epistrophe of the Earth" with its further improvement and testing can be used to form a valuable attitude to the Earth, actualization of environmental issues, formation of psychological health of participants in the educational process and actualization of the concept of sustainable development.
\end{abstract}

\section{Introduction}

Realizing the importance of futures literacy [1] and revealing the deep meanings of A. Peccei's strategies for preserving the Earth through the formation of person's qualities [2], as well as considering the value of M. Moiseev's environmental and co-evolutionary ideas [3], we actualize the educational problem of interdependent ecologization of health saving competence of the Physical Education teacher and health saving and fitness / technologies by use of Hellenistic concepts. Earth conservation issues are meaningful when considering the phenomenology of Homo Educandus health. Significant in this aspect are the understanding of the unity of a person and Earth, presented in the noospheric ideas of V. Vernadsky [4] and P. Teilhard de Chardin [5] and in the concept of "Gaia" by J. Lovelock [6]. Also decisive is humanity's understanding of its limits to growth [2,7] and, accordingly, the emergence of persistent ideas that the world is filled (the concept of "Filled World" by K. Boulding is revealed in a report by E. von Weizsaecker, A. Wijkman et al. "Come On! Capitalism, Short-termism, Population and the Destruction of

\footnotetext{
*e-mail: bruney333@yahoo.com

**e-mail: klochkoob@gmail.com
}

the Planet - A Report to the Club of Rome") [1]. Together, the methodological reflection of these concepts determines the need to develop an "anthropology of sustainable development". Accordingly, the consideration of ecophilic [8] and value transformations of Homo economikus [9] brought up on the egoistic, pragmatic, technocratic, expansive and competitive installations and rationality of the modern era into a "new person" is relevant. Such a person must be merciful, kind, non-aggressive and not expansive to the planet Earth, its resources and humanity. We call these transformations Homo Sapiens "Sustainable Development Person". This "new" anthropos (ancient Greek $\alpha \nu \theta \rho \omega \pi \mathrm{\circ} \zeta$; "Person"; lat. anthropos) should, according to the ideas of A. Pechchei [2], be harmonious, tolerant, peaceful, and moderate in its consumer and financial material "claims" to the world, nature and people.

According to the above ecophilic ideas, the professional activity of a teacher should be directed to the actualization of the physical, motor and health dimensions of person's being, which is considered in a relative and co-evolutionary way [3] with the preservation of the Earth and its harmonious interaction with it. A significant person who actively influences the formation of the "Sustainable Development Person" in the cultural and educational 
space is a Physical Education teacher and trainer. Such influence is caused by the fact that the educational interaction between Physical Education teacher and students is realized not only in the spheres of intelligence, emotions, will, communication. This interaction is formed on the basis of actualization of personally and vitally important issues of the body, physicality, bodily identity, locomotion, beauty, image, health and life. That is, it is primarily vital, aesthetically and existentially oriented.

Due to the peculiarities of professional activity, Physical Education teacher has the opportunity to contribute to the disclosure of his existential [10] through his influence on physicality and locomotion of the child [10] of temporality, space, concern, heart, health, physicality. Updating the existential dimension of the child, in addition to the exercise activity and communication, is also done through interaction with the landscape. This collectively contributes to the formation of a child's understanding of the uniqueness of our planet and, accordingly, the development of a responsible, careful and caring attitude to the Earth. Important in this context is the development in children of ideas about the need for integration ("inclusion") into a single, holistic and interdependent "Filled World" [1]. For the person of the future, the defining aspect of his identity and being is the understanding that the "Filled World" has boundaries [2,7].

In the context of the formation of a "new" "Sustainable Development Person", it is relevant to understand locomotion in psychosemantic [11] and axiological [12] meaningful personal frameworks. Accordingly, the vision of physical and fitness and health-saving technologies not only as physical (in the sense of also as motor) but also as symbolic and axiological [12] anthropopractics that contribute to the educational actualization of the problem of Earth conservation is important. The notion of motor activity as a way of forming the mental, ethical and behavioral spheres of a person has been actively used since the time of the Greek cultural and educational system of paideia (given by the Greek $\pi \alpha \iota \delta \epsilon \iota \alpha$ ) $[13,14]$. We turn to ecologically oriented actualization of the problems of the body, physicality and locomotion as one of the central and starting points in the formation of a person and in revealing the phenomenology of his health.

The need for ecologically oriented understanding of bodily anthropopractics and health-saving and physicalfitness technologies is due to systemic and systemorganizing issues of preserving not only the health but also the primo loco (above all) of the lives of children during physical education and youth. In the aspect of life preservation, the decisive and primary problem is the prevention of sudden cardiac death $[15,16]$ during physical education and youth sports. This problem is relevant to the vast majority of countries, which speaks to its connection with the environmental crisis. An urgent inclusive aspect that underlies the consideration of health and fitness technologies is the need to consider their impact on children with special educational needs. Also important is the aspect of cultural compliance of health and fitness and wellness technologies.
Thus, the development of a methodology for the development of health-saving competence of the Physical Education teacher, taking into account the greening of healthsaving and physical-health technologies is a leading problem of our study. An important aspect of the problem is that the improvement of the methodology, which includes the greening of the health-saving conduct of technologysaving on the basis of the reception and environmentally oriented interpretation of Hellenistic concepts. This problem is not sufficiently covered in the scientific pedagogical literature. This, together with the importance of this problem for the preservation of life and health of children in the educational process, makes our research relevant.

The aim of our study was to improve the methodology of development of health-saving competence of Physical Education teacher in the conditions of postgraduate education and the relative and interdependent ecologization of health-saving and physical-fitness technologies, which is realized on the basis of ecological-value reflection and the concept of sustainable ideas.

\section{Methods of the research}

This study was conducted on the basis of theoretical analysis of scientific literature and a system of approaches. Accordingly, this methodological system is represented by: competent [17], health saving [18], systemic, anthropological, cultural, historical pedagogical [13], philosophical pedagogical, reflexive, hermeneutic, axiological, epistemological, epistemological, epistemological, humanistic, geopsychological [19], ethical, preventive, psychological, existential, ontological, medical and hygienic, transdisciplinary approaches and methods.

In the system of this study, the applied conceptual and methodological potential existential pedagogy (A. Bollnow) [20], existential psychology (L. Binswager) [10] and existential philosophy; dialogical pedagogy and philosophy (N. Buber) [21]; anthropology - educational, environmental, social, historical, psychological; "earth-based psychology (A. Mindel) [19]; the philosophy of cordocentrizm; ancient spiritual educational system paideia (given by the Greek $\pi \alpha \iota \delta \epsilon \iota \alpha)[13,14,22-24]$. The topics covered were addressed using the sum concepts: sustainable development, "New enlightenment" [1], "Care for the Earth" (A. Gore) [25], the noosphere (V. Vernadsky and P. Teilhard de Chardin) [4, 5], "Gaia" (J. Lovelock) [6], a concepts of "Challenge and Response" by A. Toynbee [26], "Other" (E. Levinas) [27], the psychosemantics of motor actions (D. Donskoi, S. Dmytriev) [11], axiology motor area (I. Byhowska) [12], autopoesis (H. Maturana, F. Varella) [28], enactivism (A. Knyazeva) [29], physical rationality (J. Lakoff) [30], embodied cognitive science [31, 32]; theknowledge transfer; anthropopractics and "Technologies of the Self" (M. Foucault) [33, 34], social and cultural "construction" of health and pathology (M. Foucault) [35], subjectification (M. Foucault, S. Golenkov, A. Smirnov) [36-38]. For the purpose of ecophilic and existentially oriented interpretation of the concept of sustainable development and "the Earth Charter" [39], Hellenistic concepts were used in our study 
$[9,13,14,23,24,33,34,40-47]$ : agate (ancient Greek $\alpha \gamma \alpha \theta \mathrm{o} v$ - good), arete (ancient Greek $\alpha \rho \epsilon \tau \eta$ - charity, benefits), hubris (ancient Greek $v \beta \rho \iota \zeta$ - pride, challenge, audacity), observance to the full extent (ancient Greek $\sigma v \mu \mu \epsilon \tau \rho v, \mu \epsilon \tau \rho \iota \mathrm{v}$ ), equilibrium of forces (ancient Greek $\iota \sigma \mathrm{o} \mu \iota \eta$ ), harmony (ancient Greek $\alpha \rho \mu \mathrm{o} v \iota \alpha$ ), reflection (lat. reflexio), epistrophe (lat. epistrophe), selfknowledge (ancient Greek $\gamma \nu \omega \theta \iota \sigma \epsilon \alpha v \tau \mathrm{o} v$; french gnothi sautou) (M. Foucault) [33, 34], care of oneself (ancient Greek $\epsilon \pi \iota \mu \epsilon \epsilon \iota \alpha \sigma \epsilon \alpha v \tau \mathrm{o} v$; french epimelēsthai sautou) (M. Foucault) [33, 34].

Technique of "the Earth Epistrophe". In order to improve the health-saving competences of Physical Education teachers in postgraduate education, based on the concept of sustainable development, we have applied a value-oriented technique called "the Earth Epistrophe". This technique included elements of "body-intellectual" psycho-techniques, mental reflection, self-knowledge, as well as communicative, dialogical and moral practices. This technique is a fragment of value-oriented anthropopractics which is at the same time a pedagogical scenario, dialogue, and having a gut-wrenching interaction. Presenting this methodology, we distinguish it into three stages: I. "Disclosure of the problems of the Earth and the heart", which consists in updating the problem of preserving the Earth in relation to the issues of cardiological health and human phenomenology in general; II. "Earth Loss Modeling" which is to simulate a temporary "break" with the Earth; III. "The Earth's Epistrophe" ("Eternal Return to Earth") is the stage that is to form a model of "return" to Earth. At this stage, it is suggested to imagine a process of return to Earth, which includes, above all, the "discovery" and comprehension of the planet as a living being and as part of itself. The leading role in carrying out this technique belongs to the teacher, who acts mainly as a trainer using elements of psychocorrection and psychotherapy in his activity. Accordingly, when carrying out this technique, it is necessary to take into account the psychological state of the persons involved.

To analyze the psychological and educational effects of this exercise, we used the questionnaire formed by us "Epistrophe of the Earth". The questioning was conducted before the specified procedure and after.

Questionnaire of Fedorets-Klochko "Epistrophe of the Earth":

1. Is it easy to remember the best places you have been in your life?

2. Do you like to admire the landscapes for a long time and to remember and discuss them?

3. Do you associate your own cardiac health problems with pollution and destruction of terrestrial landscapes, forests, seas, rivers, animals (living creatures)?

4. Do you associate cardiac health problems with pollution and destruction of terrestrial landscapes, forests, seas, rivers, animals?
5. Is there any connection between the deaths of humans due to cardiac pathology and the destruction of terrestrial landscapes, forests, seas, rivers, animals?

6. Can you influence the process of conservation of the Earth and its landscapes and thus save the "Face of the Earth"?

7. Is planet Earth at least a metaphorically living being who sees, understands, and feels its destruction?

8. Do you feel in yourself and in your heart "part" of the "soul" of planet Earth?

9. Have you ever considered what the Earth will be like for your children and great-grandchildren?

10. Has your attitude towards the planet Earth and its "Face" (landscapes), rivers, seas, forests changed after an imaginary trip to "Nowhere" or "Nothing"?

The answer is formed by indicating "Yes" (+) or "No" $(-)$. We do not recommend this method with people who are psychologically unbalanced, sick and very tired. The methodology includes the demonstration of paintings and photographs of terrestrial landscapes, both preserved and destroyed in an amount of at least 20-30.

The statistical significance of the differences found in the survey results conducted among Physical Education teachers before and after the implementation of the "Epistrophe of the Earth" proprietary methodology was determined with the help of McNemar's test [48], which is also called the sign test. It allows to determine the general vector of the studied feature, i.e. it may be applied in the case when changes may be assessed only qualitatively, e.g. the change in of the negative attitude towards something into positive.

Let us mark the number of prevailing (typical) shifts as $G_{t y p}$, the number of shifts in the opposite direction (atypical) as $G_{\text {atyp }}$. The number of cases, when there was no shift (the answer did not change) will be marked as $G_{z e r}$. In McNemar's test, the shifts in which the value of the feature did not change $G_{z e r}$ are excluded from consideration.

In this case the number of pairs of $G_{z e r}$ answers, in which the value of the feature did not change, are excluded from the consideration and only the number of pairs $\mathrm{n}=G_{t y p}+G_{\text {atyp }}$ is considered. The smaller the value of $G_{\text {atyp }}$ is, the more probable it is that the shift in the typical direction is statistically viable.

In this case, two hypotheses are formulated:

$H_{0}$ - The prevalence of the typical vector of the shift is accidental;

$H_{1}$ - The prevalence of the typical vector of the shift is not accidental;

Using the statistical tables of the sign test we compute the value of $\mathrm{G}$ sign test for the levels of statistical significance at $p<0.05$ and $p<0.01$ [49]. The prevalence of a typical shift is valid, if the empiric value is $G_{\text {aty }} \leq G_{p<0.05}$ and even more valid if $G_{a t y p} \leq G_{p<0.01}$ [49] (figure 1). 


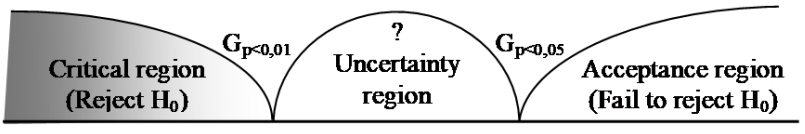

Figure 1. The Acceptance region, Critical region (Rejection region) and Uncertainty region for the McNemar's test

\section{Results and discussion}

The concept of "Tellus-Anthropic Convergence" as a methodological intention of greening. For the development of new and for the greening of existing bodily anthropopractics and health-saving [50] and physical and recreational technologies used in Physical Education classes and in general in education, we apply a system of Hellenistic concepts that reflects the ecophilicity, humanistic nature and human nature. The same concepts are an ecologically oriented component of the conceptual and methodological framework for improving the health-saving competence of Physical Education teachers. The nature of man is revealed to us in the "spirit" of the harmonization of relations in the system of "man - Earth". Our pedagogical system conducts an ethical and value-oriented update of the phenomenology of the Earth and the idea of its preservation, which is presented as a leading idea of the trend of sustainable development. As a system-organizing idea and value guideline, we use A. Gore's concept of "Caring for the Earth" [25]. A. Gore's idea is related to the value-meanings of the phenomena of anxiety, "caring for oneself", "caring for others"and thus can be organically incorporated into cultural and educational "practices of oneself". These phenomena of concern are also the defining and leading personal and behavioral qualities in the personality-existential component of the health-saving competence of a Physical Education teacher.

In this way, the idea of sustainable development and the direction of health in our methodology are interrelated, integrative, cross-cutting, systematic and defining. Accordingly, the issues of health conservation and the ideology of sustainable development underlie the transformation of methodological and technological concepts in the direction of reflecting in them the relative and interdependent preservation of both human health and the Earth. This methodological technique, as a result of which the meanings and values of preserving planet Earth are introduced into the health-saving competence of the Physical Education teacher, as well as into the health-saving and physicalhealth technologies, and also called the problem of its existential "dialogue" with human call "Tellus-Anthropic Convergence". This convergence is one of the anthropologically and existentially oriented options for greening. For clarification, we recall that Tellus (lat. Tellus) was the Roman goddess of Mother Earth.

The ethical and practical meaning of the "TellusAnthropic Convergence" is the formation, or rather the restoration and maintenance of "subtle", harmonious, proportionate, compassionate and "friendly" interactions between man and planet Earth. The conceptual feature of the "Tellus-Anthropic Convergence" as a humanistic and ex- istentially oriented methodological concept of greening is the integrative use of the ideas of existential and dialogic philosophy, care, ontologization, axiologization, psychologization, as well as ideas about planet Earth as a living being $[6,19]$ and an integral part of human existence. That is, the Earth is regarded primarily axiologically as a vital and personal value, ontologically as a special being and a spiritual or transcendental essence, as well as the EarthMother, and not only so much as a resource. The importance of the development of pedagogy with the use of transcendental meanings that can be formed as a result of the use of the potential of the ancient Greek cultural and educational system of the paideia, says Pavlos E. Michaelides [9].

Thanks to this methodological way, we actualize existential, vital, value, transcendental for the individual formats of understanding and relation to the planet Earth. Accordingly, existentially oriented aspects are contextually and in an up-to-date form incorporated into competence, in corporeal anthropopractics and in health fitness and wellness technologies. This is implemented through both the methodology and technology and practice levels.

Ecophilically interpreted Hellenistic concepts are used in several formats, namely:

1) the actual component of the conceptual and methodological foundations of this pedagogical system;

2) criteria and decisive ideas on the basis of which improvement of health-saving competence, as well as health-saving and physical health technologies are carried out;

3) the conceptual basis for the formation of questions, questionnaires, educational discourses and narratives, with gothic practices.

Competent measurement of methodological valuable reflections of ecophilicity and humanism of Hellenistic culture. In the aspect of an optimistic, innovative [51, 52] and competently oriented [17] understanding of the current environmental crisis $[1,2]$, which threatens the planet Earth, it is relevant to take into account the historical experience of ancient Greece "concentrated" in the potential of the paideia (ancient Greek $\pi \alpha \iota \delta \epsilon \iota \alpha)$ [8, 13, 14, 22, 23] and Hellenistic concepts [4, 9, 13, 14, 33, 34, 40-47]. Hellenistic culture solved the problem of resources' scarcity not only by colonizing new lands [26] but above all by unlocking the potential of man and society. That is, by moving not only "outside" into the World, but "inside" the Person, into his essence and his knowledge. This was one of the main and defining anthropologically oriented innovations of Hellenism.

An important methodological message is that Hellenism, which is at the foundation of modern rationality, science, freedom, democracy and technological power of Western civilization and humanity, has formed its humanistic concepts practically and anthropologically oriented, namely, as “technology of oneself" [33, 34, 38] or anthropopractics including corporal practices. The value of these Hellenistic concepts and the anthropopractics that underlie them lies in their focus on unlocking human potential 
by harmonizing it with the surrounding world, with Gaia (Earth). That is, we point out that these Hellenistic concepts were originally formed as ecophilic.

To some extent, the emergence of the cultural phenomenon of Ancient Greece can also be seen as a historical example of the effective use of the crisis by a perceived and "interpreted" Hellenistic culture as a stimulus to development. In this context, it can be noted that in accordance with the concept of "Call-and-Answer", A. Toynbee [26] Hellenistic culture has formed an effective response to environmental challenges [26]. And this answer was first and foremost aimed at transforming the human being in the direction of discovering his human principle, potentials of intelligence and heart, harmonization and preservation of the Earth. The answer was, in its essence, eco-friendly, humanistic, and existential.

Integrative use of Hellenistic concepts and ideas of sustainable development to improve the methodology of health-saving competence and health-saving and healthimproving technologies.

Now, before humanity, the challenges are much more complex than in the Hellenistic era. Therefore, we are talking about the need for methodological and ecologicalvalue reflection of Hellenistic concepts [4, 9, 13, 14, 33, 34, 40-47] with their appropriate use. These concepts are at the heart of this methodological system. Accordingly, we apply them to improve the methodology for developing the health-saving competence of Physical Education teachers. These concepts are also used for the selection, development and greening of health and fitness technologies aimed at the formation of "Sustainable Development Person" and the relative preservation of his health. Let us now consider the Hellenistic concept system, which consists of: agate, arete, hybrus (in the sense of counteracting hybrus), observance throughout, equilibrium of forces, harmony, epistrophe, sophrosyne, selfcare. These concepts are revealed by us in the spirit of "Tellus-Anthropic Convergence" and "Care for the Earth" [25] and are accordingly aimed at the integrative and interdependent preservation of the planet Earth and human health.

As we actualize the existential and educational aspects of the Sustainable Development Person's evolution and construct of health, we formulate the concept of "Good Human-Earth Dialogue". This concept is a refinement and further development of the idea of the TellusAnthropic Convergence that we have formed above. At the heart of this development are M. Buber's idea that dialogue is the primary ontological (existential) structure [21] and the concept of "the Other" by E. Levinas [27] where "the Other Personality", which in this case represents the Earth, is a compulsory not only for meaningful and value development, but also for existence in general.Significant aspects of our concept are the ideas of "Caring for the Earth" by A. Gore [25], "Gays" by J. Lovelock [6], the geopsychology of A. Mindel [19], the existential approaches of L. Binswager [10], the Hellenistic phenomenon of sophrosyne (ancient Greek $\sigma \omega \phi \rho \mathrm{o} \sigma v v \eta$ ) and cordocentric traditions of Ukrainian culture. By using the above system of approaches, an ecophilic and value image of the Earth is created. At the same time, on the basis of the hermeneutical approach, metaphorization, existentialization, axiologicalization, personification of the Earth are carried out. Accordingly, the Earth is seen as a living being that has a heart and soul or "at least" as a special high value and meaning. In this context, the metaphor of the heart is a relevant aspect of axiologicalization, sacralization, psychologization and existentialization of Human-Earth dialogue and understanding of this interaction as a common good for man and the planet.

As an example, let us note that the well-known technological ways that make it possible to reveal the "Benefits of dialogue between man and Earth" are: learning the ability to admire terrestrial landscapes, objects, elements; the formation of the ability to sense and "understand" the earthly elements (fire, tree, water) and phenomena (animals, plants) through the use of bodily and motor metaphors of "Merging" with them or "Reincarnation" in them. Actual is the use of bodily and motor metaphors in dynamics, in motion. At the same time, the teacher must use the potential of landscape, theater, existential [20] and popular pedagogics in the development and implementation of health and fitness and wellness technologies.

A $\gamma \alpha \theta \mathrm{ov}$ (ancient Greek) - good (agate) [13, 40, 43], is one of the central Hellenistic concepts. In the context of the ideology of sustainable development, we interpret $\alpha \gamma \alpha \theta \mathrm{o} v$ as the need to bring and "redistribute" good for both the individual and the "Other" (E. Levinas's concept of "the Other") [27] and for the planet Earth. This approach is somewhat contrary to the existing ideology of Homo Economicus [9] aimed at achieving good in the short term and only for themselves and their loved ones. The concept of sustainable development reveals to humanity as a significant "other" "person" after and "close to" man - the Earth. Accordingly, $\alpha \gamma \alpha \theta \mathrm{o} v$ for the Earth becomes an integral and essentially primary, archetypal and sacred dimension of human good, life, well-being and health. That is, the existence of a preserved Earth and the actions, meanings, values and intentions that are aimed at it are considered as high - "the Good of the Earth" [39].

As we actualize the existential and educational aspects of the Sustainable Development Person's evolution and construct of health, we formulate the concept of "Good Human-Earth Dialogue". This concept is a refinement and further development of the idea of the TellusAnthropic Convergence that we have formed above. At the heart of this development are M. Buber's idea that dialogue is the primary ontological (existential) structure [21] and the concept of "the Other" by E. Levinas [27] where "the Other Personality", which in this case represents the Earth, is a compulsory not only for meaningful and value development, but also for existence in general.Significant aspects of our concept are the ideas of "Caring for the Earth" by A. Gore [25], "Gays" by J. Lovelock [6], the geopsychology of A. Mindel [19], the existential approaches of L. Binswager [10], the Hellenistic phenomenon of sophrosyne (ancient Greek $\sigma \omega \phi \rho 0 \sigma v v \eta$ ) and cordocentric traditions of Ukrainian culture. By using the above system of approaches, an ecophilic and value image of the Earth is created. At the same time, on the basis of 
the hermeneutical approach, metaphorization, existentialization, axiologicalization, personification of the Earth are carried out. Accordingly, the Earth is seen as a living being that has a heart and soul or "at least" as a special high value and meaning. In this context, the metaphor of the heart is a relevant aspect of axiologicalization, sacralization, psychologization and existentialization of Human-Earth dialogue and understanding of this interaction as a common good for man and the planet.

As an example, let us note that the well-known technological ways that make it possible to reveal the "Benefits of dialogue between man and Earth" are: learning the ability to admire terrestrial landscapes, objects, elements; the formation of the ability to sense and "understand" the earthly elements (fire, tree, water) and phenomena (animals, plants) through the use of bodily and motor metaphors of "Merging" with them or "Reincarnation" in them. Actual is the use of bodily and motor metaphors in dynamics, in motion. At the same time, the teacher must use the potential of landscape, theater, existential [20] and popular pedagogics in the development and implementation of health and fitness and wellness technologies.

$A \rho \epsilon \tau \eta$ (ancient Greek) - arete or virtues (virtue, perfection, excellence, high quality, nobility) is one of the systematic Hellenistic concepts [9, 13], (Dialogue of Plato "Menon") [42]. In the context of the health-saving issues of physical culture and sport, the Hellenistic concept of bodily arena [16], among which health, strength, beauty, is important. As in the past, we are updating the need to focus health care competences and fitness technologies on the arete, including the physical. At the same time,into the dimensions of arete it is suggested to bring connotations of the meanings of the Earth's preservation.

We consider the health-saving competence of a Physical Education teacher as a high level of training to be a "professional arete". In the era of postmodern competence [53] and professionalism have essentially become system-organizing sociocultural factors or "major" aretes forcing others out. According to the "competence" "transformations" [20], the connection of bodily aretes with the image of the person, the existential dimension, with social adaptation, inclusion in society and profession, as well as with personal development, actualization and self-realization is relevant.

In the previous industrial era, physical training was directed to the formation of certain qualities (mainly strength, endurance) as isolated functions that could be used for war and production. Let's mention the Soviet functionally oriented system of TRP ("Ready for work and defense"). Reducing in essence and functionally oriented "models" of man in the modern era speaks L. Marcelle [54]. It is clear that such a "military-industrial" approach ignored the problem of ecophilicity, existential and psychological health, and diminished the possibilities of choice, etc.

Now, given the ecocentric and human-centered tendencies and methodological potential of the ideas of "Revolutionary Humanism" (A. Peccei) [2], one can say that the development of physical qualities of a person that collectively participate in the formation of not only force or en- durance, but above all beauty, health, image, intelligence, professional and social and environmental adaptation, and bring joy and happiness to man. Beauty, health, life, happiness are existential values in the understanding of which a person consciously or unconsciously incorporates into his existence a relevant "background" - the Earth. Therefore, the actualization of the existential dimension $[10,18]$ both in health-saving competence and in the implementation of physical and fitness technologies is a way of "returning" a person not only to himself but also to planet Earth. In this case, the Earth should become a "living space" and a part of life "being included"in the existential space, rather than being a "neutral" environment.

Using the idea of sustainable development and "the Earth Charter" [39], we formulate the concept of "Earth's Arete" ("Earth's Virtue"), to which we refer: "Care for the Earth [25]; love for the Earth; the ability to admire the landscapes of the Earth and its "things", plants, animals; responsibility for the Earth; respect for the Earth; fear of possible Earth damage and other ecophilic qualities, installations and intentions. The concept of "Earth's Arete" reflects the high virtue of a person who manifests himself in a responsible, caring, kind and warm attitude towards the Earth. This concept is different from the Platonic idea of "Earth's Arete" [55], which reveals the quality of the Earth itself. Thus, the improvement of the health-saving competence of the Physical Education teacher should be carried out with the actualization of the idea of "Earth's Arete", the use of which in physical culture-improving technologies is existentially oriented through greening.

In confirmation of the relevance of our existentially and environmentally oriented "arete approach", we refer to the direction of psychotherapy - arete-therapy, which was developed in 1917 by the Russian physician I. Yarotsky [56]. This method consisted in updating the arete primarily of an altruistic character for therapeutic purposes. To preserve the Earth, the manifestation of altruism will be "the Earth's Arete", which can provide a person with the stability of his health and life.

Hubris counteraction. Hubris (ancient Greek $v \beta \rho \iota \zeta$ ) - pride (boldness, excessive vanity) is one of the current Hellenistic concepts [42, 46]. The ancient Greek goddess Hubris could lead a person to the vicissitudes (ancient Greek $\pi \epsilon \rho \iota \pi \epsilon \tau \epsilon \iota \alpha)$ of the essence of which is the destruction of available opportunities, resources and the disappearance of luck. The next stage was nemesis (ancient Greek $v \epsilon \mu \epsilon \sigma(\zeta)$ - divine revenge, destruction and death. Therefore, "immersion" in the deep essence of this concept opens the way to self-improvement and the formation of optimal life strategies by avoiding the hubris and "purifying" from it.

Nowadays, as in the ancient era, the restriction of a hubris is relevant because it is often the basis of the overstated requirements and needs of humans and their incorrect or "hubris" behavior. Hubris result in excessive resources, which must be taken into account when implementing the concept of sustainable development. In physical culture and sports, hubris are often the result of illness or even death. This happens when a person wants to demonstrate to himself or someone "special" physi- 
cal and motor abilities and athletic performance without considering the level of fitness and health and neglecting common sense, expediency, life meaning and values. An example of hubrisity in education is the pathos-infused "Day of Health", which sometimes ends in illness or even the death of its participants. This is due to the fact that people who do not have the appropriate level of training demonstrate "special" sport results. Another example is the active use of anabolic drugs in bodybuilding in order to rapidly "build up" muscle volume.

Therefore, there must be a limit and a measure of agonizing and demonstrative physical culture, which can be transformed into a continuous competition, struggle and race. In our opinion, hubris is one of the causes of children's death from sudden cardiac attack [57] at Physical Education lessons and youth sports. Physical Education teacher needs to develop such professional settings and a health-friendly environment where the hubris is minimized. This will eliminate the achievement of a training or competitive result at the cost of disrupting the health or life of the students. It is also important to minimize the "hubris" in its essence of the assessment of the work of a Physical Education teacher, namely by the performance of his students at competitions or other events.

The hubris is one of the socio-political, psychological and cultural factors for the destruction of the Earth. Therefore, knowledge of it and its limitation in the profession of Physical Education teacher promotes the concept of sustainable development and preservation of health. Hubris can be minimized by displacing them through the formation of "Earth's Arete" in children, sophrosyne (ancient Greek $\sigma \omega \phi \rho \sigma v v \eta$ - moderation, prudence), modesty, and through the development of a tolerant and compassionate attitude toward one another.

$\Sigma v \mu \mu \epsilon \tau \rho \mathrm{ov}, \mu \epsilon \tau \rho \iota \mathrm{ov}$ (ancient Greek) - being moderate in everything [27], is an important concept that reflects the proportionality of the nature of man and the world around him. Plato considers the problem of measure in the dialogues "The Philebus" [43], and "The Phædo" [42]. In ancient Greeks, the Goddess Nemesis was a symbol of measure. It is interesting that Nemesis was also the Goddess of revenge, which came when a man neglected the measure. This is what we see in our world. The Nemesis of the Earth "creates" revenge for humankind for its destruction, which manifests itself in the form of environmental and climatic problems and disasters.

The measure was an ethical, aesthetic, spaceontological notion of Hellenistic philosophy, culture, paideia (ancient Greek $\pi \alpha \iota \delta \epsilon \iota \alpha$ ) [13], gymnastics and medicine. The measure was a methodological, ideological and spiritual basis for understanding and updating the phenomena of moderation, proportionality, proportion, symmetry, boundaries, harmony, cosmic order, good, arete, beauty, ethics, aesthetics.

Specifying that the Hellenistic understanding of the measure was quite varied and included meros("measure") ("Timaeus dialogue"), metrios ("moderation", "moderate") ("State"), emmetros ("measured"), symmetria ("commensurate") ("The Philebus dialogue") [43], mesos ("middle", "center"), mesotes ("center", "centrality"). The idea of the measure permeated the life of the ancient Greek policy by effectively competing with the intensities of expansive growth, accumulation and expansion inherent in modern consumer civilization. A. Peccei [2] and D. Meadows [7] reveal to mankind in all intellectual power and noumenal grandeur the conceptual and ecophilic potentials of the phenomenon of the boundaries, in which the idea of the measure of human influence on Earth is represented.

The implementation of physical anthropopractics and health and wellness technologies, as well as the improvement of health-saving competence, must take into account the grand idea of $M \epsilon \tau \rho \iota \mathrm{v}$ (measures). This is relevant because even in a professional environment, there is an idea of the need for "constant movement activity" without sufficient consideration of the phenomenology of the organism and life. At the heart of this nihilistic "idea" is the setting of neglect and a "professional hybris". Lack of measure and moderation in the training process is a way that increases the risk of acute cardiac pathology.

In accordance with the concept of embodied rationality by J. Lakoff, the basis of our cognitive activity are physical phenomena [30]. Based on the conceptual potential and corporeal orientation of "corporeal rationality" [30], embodied cognitive science [31, 32], autopoiesis [28], enactivism [29] can be said that physical culture is one of the defining disciplines that contributes to the development of the ability to comply with the measure. This is due to the fact that within the stated directions the observance of the measure is formed through the body, bodily and motor experiences, practices, reflections, metaphors, scenarios. The understanding of the measure develops through bodily anthropopractics, health and physical and fitness technologies through the interactivity of locomotor sensations, through the development of motor intelligence and reflection, which is a precondition for a person to understand his boundaries and opportunities.

In order to teach the measure, it is important to reveal to the students the phenomenology of the Earth as systemic and interdependent with human integrity. In this aspect, care of the forest, garden, lawn, and pets is also relevant, so that care and measure are formed. In line with these ideas, we present an environmentally-friendly concept of "Complying with the Measure in Active Impact on Earth". The purpose of this concept is to develop in children the attitude and skills of observing the measure as a special "Arete of the Earth" and understanding the inadmissibility of crossing borders in active (economic and other) influences on the Earth.

$I \sigma \mathrm{ovo} \mu \iota \eta$ (ancient Greek) - the equilibrium of forces $[13,31]$ is a relevant Hellenistic concept that reveals the deep essence of both human health and the well-being of the Earth. A modern physiological and biochemical concept that is formed on the basis of the idea of equilibrium of forces is homeostasis. In the context of our problematic, the actualization of the idea of equilibrium of forces in the system "man - Earth" is revealed in the concept of sustainable development.

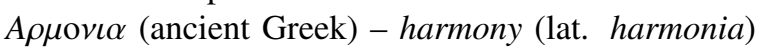
is one of the main and defining Hellenistic concepts. In 
the Greek pantheon, the goddess Harmony was the daughter of Ares (god of war) and Aphrodite. It embodied the idea of family harmony and represented the personalized essence of the combination of opposites. In addition to proportionality, harmony is about consolidation, beauty, invisibility. Plato in the dialogues "Timaeus" [43], "Phædo" [42], "Philebus" [43], "Banquet" ("Symposium" $(\Sigma v \mu \pi \mathrm{o} \leftarrow \iota v)$ [42], "State" [43], revealed harmony as a manifestation of the high, immortal, divine in man, and also illuminated its cosmic-ontological dimension in the form of "harmony of spheres" (ancient Greek $\alpha \rho \mu \mathrm{ov} \iota \alpha \epsilon v$ $\kappa \mathrm{0} \sigma \mu \omega, \eta \tau \mathrm{o} v \pi \alpha \nu \tau \mathrm{O} \zeta \alpha \rho \mu \mathrm{o} \nu \alpha$; lat. harmonia mundi).

The formation of harmony in the person, namely between his physical and mental and spiritual dimensions, is relevant. Therefore, one of the central health aspects is the question of harmonious relations in the "pairs" of phenomena, namely between: bodily and intellectual, bodily and spiritual, man and Earth. Formation of harmony in man himself is a precondition for the harmonization of his relations with the Earth. At the same time, a harmonious relationship between man and Earth is a condition for actualization, personal growth and peace of mind.

In this aspect it is necessary to take into account that disturbance of harmony between physical and spiritual and mental, leads to neuroticism and psychopathization (persistent maladaptive and disharmonious changes in character) of the person. There is such a pathology of character as somatotonia [58], which may arise due to the excessive concentration of the human body. Somatotonia can be seen as a manifestation of hybris when the physical arete (health, beauty, strength) begins to dominate the spiritual and mental being - intellect, ethics, etc. Sometimes somatotonia is found in athletes and sportsmen. Physical education and sport should be used in a proportionate manner to human nature and promote the harmonization of the individual. Therefore, when organizing motor activity, it is necessary to take into account the risks of unpredictable "somatotonia", "hubris" "effect". The essence of it is a violation of human harmony. In this case, the person may become rude, arrogant, aggressive, primitive, prone to chemical dependencies. The reason for this would be an over-enthusiasm for physical culture or sports that is not balanced by spiritual and intellectual being and perfection.

Adapting the idea of harmony to our methodological system, we formulate the concept of "Tellus-Anthropic Harmonization", the meaning of which is the use of health-saving competence and physical and fitness technologies for the improvement of man and for his personal growth in a relative and "inseparable" way, while preserving formation of this harmony in the system "Man-Earth". Within this concept, the preserving competence of a Physical Education teacher is regarded as a personal and professional instrument of harmonization of the same person, formed on the basis of ecophilic and terracentric intentions and values. An example of such harmonization is a walk in a park or forest when the Earth, through interaction with man, "reveals" in him the best sides of the soul. It is valuable to take a walk or a rhythmic run, which helps to create the effect of self-knowledge correlated with the disclosure of the beauty and "soul" of the landscape and the "heart" of the Earth.

Epistrophe (lat.) - the epistrophe represents the Hellenistic idea, the essence of which is eternal return [44]. Epistrophe in our interpretation is a topical ecophilic concept, which aims at understanding man himself and his being in the form of a constant or cyclic return to himself and to the Earth as a planet and place of life, as well as "finding" himself as an "ideal" and healthy person. That is, a return to Earth as in the Garden of Eden. The epistrophe idea is contextually embedded in spiritual anthropopractics, including prayer, yoga. In the epistrophe, there are meanings of renewal, improvement, transformation, revival of the individual through his return to the "ideal state". In this case, such an ideal is to unveil the grandeur, beauty, vitality, value and being of the Earth. So, a person needs to constantly work to return the "paradise" Earth that it was before the industrialization era. To return such Earth to the very person primo loco (primarily) one must return to oneself by becoming an ecophilic "Sustainable Development Person" and not remain an "industrial-agricultural predator".

We actualize the idea of an epistrophe, which is interpreted as the need for a "permanent and eternal" return of the planet Earth in its primordial beauty, paradise beauty, power, vitality and diversity. Accordingly, relevant is the "eternal return" of man to himself and "finding" himself, his integrity, identity, mind, physicality, capabilities, power through interaction and dialogue with the Earth and on the saved planet.

The constant orientation of a person to save and prosper the Earth both in the present and in the distant future, as well as the ability to understand and prevent the problems of the planet as our own, we consider in the format of the concept "Earth Epistrophe" ("Eternal return to Earth"). This concept includes in its composition the ability to existentially-value understanding of the Earth and to understand it as a special being and a constant life purpose to which high human intentions, dreams and actions are directed. Earth's epistrophe as a complex and "global" feeling is well understood by astronauts and humans who have nostalgia for their homeland. That is why expatriates who are nostalgic are "forever returning" to their homeland in dreams and in the desire to at least help their land. We consider patriotism a form (or a particular case) of the manifestation of the "Earth's Epistrophe" which is inherent in the nature of man, both terrestrial and cosmic.

$\Sigma \omega \phi$ o $\sigma v v \eta$ (ancient Greek) - sophrosyne is a significant Hellenistic concept. The sophrosyne reflects the phenomenology of a prudent, harmonious and moderate character and a developed life-giving intelligence that defines a socially and environmentally acceptable style of behavior and harmonizes one's own life. The phenomenon of sophrosyne is revealed by Plato in his work "The State" [43], and in the dialogues "Charmides" [41] and "AlcibiadesI" [41]. Sophrosyne is a complex integrative character, spiritual and mental quality, which is a system formed by many components. The composition of Sophrosyne includes: moderation, common sense, prudence, restraint, harmony, ethical orientation. Sophrosyne also contains 
skills of reflection, self-discovery, social communication, foresight, planning, order and consistency, as well as the ability to maintain health and the ability to master the arts and technological skills.

We consider sophrosyne as a defining, integrating and central phenomenon of the character, behavior and mental sphere of the "Sustainable Development Person", because this quality has the potential of moderation, harmony, measure and understanding of its limits of influence. Contextually sophrosyne is an ecophilic quality, because a harmonious and moderate person is not inherently a destroyer of either the environment or himself. In the Ukrainian tradition, sophrosyne was a moderate, balanced, compassionate and kind person [24]. Moderation and prudence in the Ukrainian tradition as well as in the Hellenistic were valued more than special intelligence, beauty or other arete. Thus the sophrosyne reflects the harmonious and high in nature of man (ancient Greek $\phi v \sigma \iota \zeta \tau \mathrm{o} v \alpha \nu \theta \rho \omega \pi \mathrm{o} v$ ) and the idea of its sustainable existence, as well as the ability to live peacefully with others, with the environment, with the Earth, and the ability to preserve oneself, their own authenticity and personality.

Presence of a formed sophrosyne in a Physical Education teacher minimizes the risks of using excessive, disarming and incorrect physical activities in the educational process, and also limits the creation of total competition and race. This, in turn, is a pedagogical condition for the prevention of sudden cardiac death and other acute cardiac pathology. Sophrosyne is essentially a manifestation of "sustainability and harmony of personality", which is a precondition for optimal, non-expansive, peaceful, healthsaving and "economical" and low-cost interaction with the environment.

Sustainability, harmony, balance and moderation as components of sophrosyne are correlated with the trend and ideology of sustainable development. Metaphorically speaking, one can say that sustainable development is the "sophrosyne of humanity". That is, the conservation of the Earth requires the formation of sophrosyne both on the personal and metasystem ethnic, political, social, managerial and terrestrial levels. In our view, the development of sophrosynewill contribute to the formation of a unified terracentric and "ecophilic world" through actualization of tolerance, moderation, harmony, discretion, peacefulness, effective intercultural communication and preservation of health. We actualize the eco-oriented issue of the need for the development of sophrosyne as a defining component of the personal-existential component of the health-saving competence of a Physical Education teacher [24]. Accordingly, the development of sophrosyne in students through the use of health-saving and physical-fitness technologies is relevant.

Epimelēsthai sautou - "taking care of oneself" is a culturally significant Hellenistic concept and "technology of self" (according to M. Foucault) [33, 34], which included taking care of the body, soul, family, students, and the Delphic principle "extended" to the anthropopractics of self-knowledge (gnothi sautou). Epimelēsthai sautou is covered by Plato in his dialogues "Alcibiades I" [41] in "The Apology of Socrates" [41]. The anthropological value and life value of the epimelessthai sautou for contemporaries was revealed by M. Foucault [33, 34]. Caring for oneself was a central anthropopractics in Hellenistic culture. Ideas and traditions close to "taking care of yourself" exist in other cultures. The Ukrainian culture has a tradition of "handling himself". It is, in its essence, some analogue of the Hellenistic epimelēsthai sautou.

In accordance with the ecocentric meanings of the concept of sustainable development, we are updating the question of the need to use the Hellenistic concept of epimelēsthai sautou in a modern interpretation with the inclusion of A. Gore [25] and "Tellus-Anthropic Convergence" ideas in his semantic sense. The ecophilic significance of the epimelessthai sautou is that due to this anthropopractics, the responsibility of the individual and his ability to reasonably and moderately (in the "sophrosyne" spirit) take into account the Earth's resources and their own potential. Epimelēsthai sautou in combination with "Care for the Earth" [25] is an ecophilic way of integrating and putting into practice the concepts and phenomena presented above.

In concluding the Hellenistic concepts used in this methodology, we pay attention to their spiritual and transcendental dimensions and balancing and harmonizing character, as well as to the inexhaustible intellectual-value, hermeneutic and existential potentials, and deep wisdom, eccentricity, ecophility. This makes these Hellenistic concepts and anthropopractics and technologies formed on their basis effective instruments of ecophilic and humanistically directed realization of the idea of sustainable development, ways of subjectivity and development of professional subjectivity and health-saving competence of the teacher of Physical Education, as well as conceptually methodological health conditions.

Testing of the method of "Epistrophe of the Earth". For the purpose of forming a value relationship to the Earth and for the development of the Earth's Arete (Earth Virtue), the Concern for the Earth, and for promoting the processes of forming a unified world, we conducted research using the Earth Epistrophe (described above in section methods). A significant aspect of this technique is the attempt to form or more accurately expose "the Existential of the Earth" in Physical Education teachers. We consider the development of a valuable attitude to the planet Earth and the formation of the "Arete of the Earth" as an actual component of psychological health.

The study involved 157 Physical Education teachers who have received advanced training. The research was conducted in 2017-2018 at the Drohobych Ivan Franko State Pedagogical University (Institute of Postgraduate Education), Chernihiv Regional Institute of Postgraduate Pedagogical Education named after K. D. Ushynsky, Sumy Regional Institute of Postgraduate Pedagogical Education, Mykolaiv Regional Institute of Postgraduate Pedagogical Education.

When interviewed for "the Epistrophe Earth" method, the number of positive and negative answers was $76 \%$ and $24 \%$, accordingly (figure 2).

After conducting "the Epistrophe Earth" method, the result of the questionnaire determined the change in the 


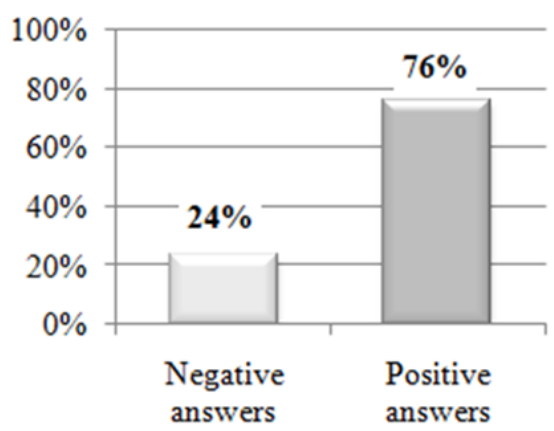

Figure 2. The results of the questionnaire of Physical Education teachers in order to determine the value relationship to the planet Earth carried out before the method of "Earth Epistrophe"

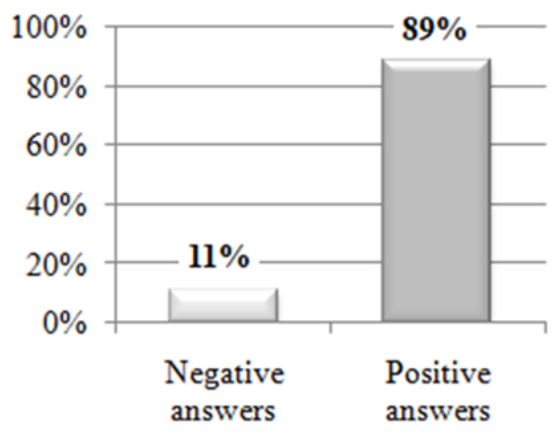

Figure 3. The results of the questionnaire of Physical Education teachers in order to determine the value relationship to the planet Earth was carried out after carrying out the method of "the Earth Epistrophe"

specified proportion - an increase in positive answers, accordingly $89 \%$ and $11 \%$ (figure 3 ).

As it is seen from figure 2 and figure 3, after the application of the methodology of development of a valuebased attitude towards the Planet Earth and the formation of the "Arete of the Earth", the number of positive students' answers in the questionnairs increased. Using the McNemar's test, lets us prove that this positive shift is prevailing [48].

According to the received survey results, the number of prevailing (typical) shifts was $G_{t y p}=220$, the number of shifts in the opposite direction (atypical) was $G_{a t y p}=16$. The sum of positive and negative shifts is $n=G_{\text {typ }}+G_{\text {atyp }}=220+16=236$.

Let's formulate the hypotheses.

$H_{0}$ - the shift in the direction of a positive attitude towards the Earth and the formation of the "Arete of the Earth" is accidental;

$H_{1}$ - the shift in the direction of a positive attitude towards the Earth and the formation of the "Arete of the Earth" is not accidental.

Using the tables, we determine the critical value of the $G$ sign test [49]. This table indicates critical values of the sign test for $n=220$ and $n=240$. We select the value

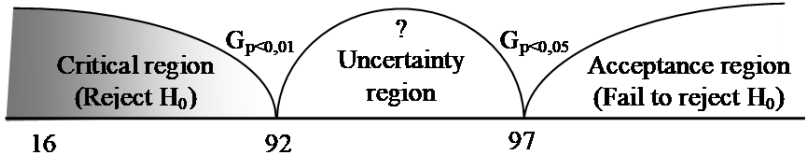

Figure 4. The Significance region (Critical region) for the McNemar's test, the shift in the direction of a more positive attitude towards the Earth and the formation of the "Arete of the Earth" is not accidental

of the sign test $G_{p<0.05}$ and $G_{p<0.01} n=220$, as they are more severe than those for $n=240$. Thus, for $n=220$ $G_{p<0.05}=97$ and $G_{p<0.01}=92$. These are the maximum numbers atypical shifts under which the shift in the direction of a more positive attitude towards the Earth and the formation of the "Arete of the Earth" is not accidental and may be considered viable.

In our case, $G_{a t y p} \leq G_{p<0.01}$ as $16 \leq 92$ (figure 4). The $H_{0}$ is declined. The $H$. hypotheses is accepted. According to it, the shift in the direction of a more positive attitude towards the Earth and the formation of the "Arete of the Earth" is not accidental. Thus, the statistical significance of the differences determined by the survey results conducted among Physical Education teachers before and after the implementation of the "Epistrophe of the Earth" propriety methodology in order to determine the level of formation of a value-based attitude towards Planet Earth and the formation of the "Arete of the Earth" is significant and viable.

\section{Conclusion}

In this study, through the ecologically and terracentrically oriented interpretation of Hellenistic concepts, the innovative, methodological and humanistic potential of the concept of sustainable development is revealed. The Hellenistic concepts fully reflect the ecophilic, humanistic and intellectual essence of a person, which determines their methodological and practical value and expediency of use in modern pedagogical systems. The idea of sustainable development revealed through ecophilic interpretation of Hellenistic concepts is presented as a conceptual and methodological basis for improving the health-saving competence of Physical Education teachers in postgraduate education. Accordingly, the concept of sustainable development is also highlighted as a significant methodologically valuable condition for the greening of health and fitness technologies.

On the basis of ecologically valuable reflection of the ideology of sustainable development, "the Earth Charter", noospheric and geopsychological doctrines and Hellenistic ideas, we develop methodological concepts of "Tellus-Anthropic Convergence", "Good of the Dialogue of Man and Earth", "Arete of Earth", "Compliance with Active Impact on Earth", "Tellus Anthropic Harmonization", "Earth Epistrophe". These concepts can be used by the Physical Education teacher at both the methodology level in the design of training classes and programs, as well as in educational health and wellness technologies 
and practices. The system-organizing concept of TellusAnthropic Convergence is presented as an existential value and health-oriented version of greening. The essence of this concept is the idea of convergence, rapprochement, as well as the restoration and preservation of the existential dialogue of man and the Earth, which is represented as: the basis of being, life meaning and existential value. This concept discloses an innovative and existentiallydialogically oriented interpretation of the idea of sustainable development and the global and life-giving meanings of "the Earth Charter".

In order to form a value relation to the Earth, to develop the "Arete of the Earth" and to unveil the "Existential of the Earth", we used the value-oriented reflexive technique of the "Epistrophe of the Earth". Based on the analysis of the conducted questionnaire, we can draw the following conclusions:

1) the problem of Earth conservation and sustainable development is relevant among Physical Education teachers; the Earth Epistrophe technique promotes the spreading of Earth conservation values and their transformation into personally meaningful ones for the teacher;

2) the method of "Epistrophe of the Earth" with its further improvement and testing can be used to form a valuable attitude to the Earth, actualization of environmental issues, formation of psychological health of participants in the educational process and actualization of the concept of sustainable development.

According to the survey results and conclusions regarding the statistical significance of the differences between these results determined with the help of McNemar's test, a conclusion may be drawn regarding the efficiency of the "Epistrophe of the Earth" propriety methodology, implemented with the aim of forming the health preserving competence of a Physical Education teacher. This conclusion is based on the fact that $G_{\text {atyp }} \leq G_{p<0.01}$, as $16 \leq 92$. Thus, the empiric value of $G_{a t y p}=16$ is in the insignificance zone as it is considerably lower than the table value of $G_{p<0.01}=92$, which indicates a high level of probability that the differences in the received results are viable and not accidental.

On the basis of ecological value and mystical reflection of the problem of Earth conservation, the question of determining the ecophilic ways of human development of the future - "Sustainable Development Person" is actualized. In addition to ecocentric intentions, values and attitudes, sophrosyne is the leading personality-behavioral and mental quality of Sustainable Development. The Hellenistic concept of sophrosyne is a complex harmonized system of personal and mental qualities integrated on the basis of moderation and harmony. Among the components of sophrosyne, ecophilic and important for maintaining health are such personality and behavioral qualities as: moderation, common sense, prudence, harmony, restraint, sense of self-care, self-knowledge, caution, self-restraint, etc. To save the planet it can be moderate and harmonious man, who with the Earth and with himself exists in har- mony, and is accordingly restrained in expansive and destructive desires, plans and actions.

Metaphorically, we regard the concept of sustainable development as the "sophrosyne of humanity", as the ecophilic cultural code of the global world, and as a noospheric self-preserving intention. Sophrosyne can also be considered the personal and psychological basis of a harmonious, life-giving and sustainable existence of man. Accordingly, the development and realization of the health-saving competence of a Physical Education teacher involves the formation of sophrosyne both in him and in the students. In this case, sophrosyne is a cross-cutting, systematic and determining personalitybehavioral and mental quality that ensures the preservation of psychological, physical and social health.

The development of sophrosyne is one of the pedagogical and personal-professional conditions for the prevention of sudden cardiac death and other acute cardiac pathology in Physical Education. This is due to the fact that the person who has developed sophrosyne minimizes risky, stressful, provocative, "hybrid" (caused by pride, excessive self-love, demonstrative), extreme, expansive behavior and understand the limits of their capabilities. Thus, sophrosyne minimizes the impact of psychological and social conditions on the development of stress and extreme overload on the body. Accordingly, the likelihood of the formation of dangerous life situations and the possibility of the development of etiological (causal) factors of cardiac pathology. Harmonious and moderate "Sustainable Development Man" does not create stress, problems and troubles for himself, his heart, neither to others, nor to the Earth. Thus, from a professional standpoint, we view the development of sophrosyne as a competent and personally-oriented way of greening, harmonizing and axiologizing the health-saving competences of Physical Education teachers and physical health technologies and practices.

Sophrosyne is also an educational condition for the formation of an "ecophilic future" and the preservation of health and life through the harmonization of human relations with himself, with planet Earth, with the future and with society. Motor activity, which is a manifestation of human nature and, accordingly, the main activity in Physical Education classes is presented as an effective way of forming sophrosyne.

\section{References}

[1] E. von Weizsacker, A. Wijkman, et al., Come On! Capitalism, Short-termism, Population and the Destruction of the Planet (Springer, New York, 2018)

[2] A. Peccei, The human quality (Pergamon Press Ltd., Oxford, 1977)

[3] N.N. Moiseev, Russian Studies in Philosophy 37, 63 (1998)

[4] V.I. Vernadsky, The biosphere and noosphere (Nauka, Moskva, 1989)

[5] P. Teilhard de Chardin, The human phenomenon (Sussex Academic Press, Portland, 2015) 
[6] J. Lovelock, The vanishing face of Gaia: A final warning: Enjoy It While You Can (Allen Lane, London, 2009)

[7] D.H. Meadows, D.L. Meadows, J. Randers, W.W. Behrens III, The limits to growth (Universe Books, New York, 1972)

[8] S.A. Zubkov, Manuskript 12, 140 (2019)

[9] P.E. Michaelides, International Journal of Arts \& Sciences 11, 77 (2018)

[10] L. Binswanger, Being-in-the-world: Introduction to existential psychiatry (Juventa, St. Petersburg, 1999)

[11] D.D. Donskoy, S.V. Dmitriev, Teoriya i praktika fizicheskoy kulturyi 9, 2 (1999)

[12] I.M. Byihovskaya, Fizicheskaya kultura: vospitanie, obrazovanie, trenirovka 2, 19 (1996)

[13] W. Jaeger, Pajdejya. Vospitanie antichnogo greka (Paideia. The education of the ancient Greek) (Greko-latin. kabinet Yu. A. Shichalina, Moskva, 1997)

[14] M. Ibrahimov, Visnyk Zhytomyrskoho derzhavnoho universytetu imeni Ivana Franka 1, 9 (2014)

[15] B. Kuvaki, S. Ozbilgin, Turkish Journal of Anaesthesiology \& Reanimation 46, 170 (2018)

[16] M. Ackerman, D.L. Atkins, J.K. Triedman, Circulation 133, 1006 (2016)

[17] D. Raven, O.N. Yaryigin, A.A. Korostelev, Azimut nauchnyih issledovaniy: pedagogika i psihologiya $\mathbf{6}$, 167 (1997)

[18] V.M. Fedorets, O.V. Klochko, Visnyk Chernihivskoho natsionalnoho universytetu imeni T.H. Shevchenka 3, 223 (2019)

[19] A. Mindell, Geopsihologiya v shamanizme, fizike $i$ daosizme. Osoznanie puti: $V$ ucheniyah Dona Huana, Richarda Feymana i Lao tsyi (Earth-Based Psychology in Shamanism, Physics and Taoism. Path Awareness: In the Teachings of Don Juan, Richard Feynman and Lao Tse) (Ganga, Moskva, 2008)

[20] O.F. Bollnow, Neue Geborgenheit: Das Problem einer Überwindung des Existentialismus (Kohlhammer, Stuttgart, 1955)

[21] M. Buber, Ya i tyi (You and I) (Politizdat, Moskva, 1992)

[22] J. Dillon, Educational Philosophy And Theory 50, 597 (2017)

[23] V.M. Fedorets, Visnyk pisliadyplomnoi osvity 8, 153 (2019)

[24] V.M. Fedorets, Nova pedahohichna dumka 2, 175 (2019)

[25] A. Gore, Earth in the Balance: Ecology and the Human Spirit (Houghton Mifflin Company, New York, 2006)

[26] A.J. Toynbee, A Study of History (Oxford University Press, 1934-1961)

[27] E. Levinas, Vremya i drugoy (Time and another) (Vyssh. Religious Philosophy shk., St. Petersburg, 1998)

[28] H.R. Maturana, F.J. Varela, The Tree of Knowledge: The Biological Roots of Human Understand- ing (Shambhala, 1992)

[29] E.N. Knyazeva, Enaktivizm: novaya forma konstruktivizma $v$ epistemologii (Enactivism: A new form of constructivism in epistemology) (Tsentr gumanitarnyih initsiativ, Moskva, 2011)

[30] G. Lakoff, M. Johnson, Metaphor we live by (The University of Chicago Press, Chicago and London, 1980)

[31] L. Shapiro, Philosophy compass 2, 338 (2007)

[32] A.A. Chikin, Filosofskie nauki 11, 140 (2012)

[33] M. Foucault, Technologies of the Self: Lectures at University of Vermont Oct. 1982 (University of Massachusets Press, Cambridge, 1988)

[34] M. Foucault, The History of Sexuality, Vol. 3: The Care of the Self (Vintage, 1998)

[35] M. Foucault, The Birth of the Clinic: An Archaeology of Medical Perception, 3rd edn. (Routledge, 2003)

[36] M. Foucault, Intellektual i vlast: Izbrannyi politicheski stati, vyistupleni $i$ interv (The Intellectual and Power: Politically Selected Articles, Speeches and Interviews) (Praksis, Moskva, 2006)

[37] S.I. Golenkov, Vestnik Samarskoy gumanitarnoy akademii 1, 54 (2007)

[38] A.E. Smirnov, Ph.D. thesis, Buryatskiy gosudarstvennyiy universitet, Ulan-Ude, Russia (2012)

[39] The earth charter (2020), https://earthcharter.org/read-the-earth-charter/

[40] V.L. Kurabtsev, Platon: agatofilosofiya (Plato: Agathophilosophy) (Prospekt, Moskva, 2016)

[41] Platon, Sobranie sochineniy v chetyireh tomah (Collected works in four volumes), Vol. 1 (Myisl, Moskva, 1990)

[42] Platon, Sobranie sochineniy v chetyireh tomah (Collected works in four volumes), Vol. 2 (Izd-vo Olega Abyishko, St. Petersburg, 2007)

[43] Platon, Sobranie sochineniy v chetyireh tomah (Collected works in four volumes), Vol. 3 (Izd-vo Olega Abyishko, St. Petersburg, 2007)

[44] P. Prokl, Pervoosnovyi teologii: Gimnyi (The first principles of theology: Hymns) (Progress, Moskva, 1993)

[45] Aristotel, Sochineniya v chetyireh tomah (Writings in four volumes), Vol. 1 (Myisl, Moskva, 1976)

[46] O.P. Zubets, Eticheskaya myisl 7, 171 (2006)

[47] A.F. Losev, Komentarii k dialogam Platona, Harmid (Comments on Plato's dialogues, Harmid) (PSYLIB, Kiev, 2005)

[48] R. McCall, Fundamental Statistics for Psychology (Harcourt Brace \& World, New York, 1970)

[49] D.B. Owen, Handbook of statistical tables (AddisonWesley Publishing, London, 1962)

[50] S.V. Garkusha, Formuvannya gotovnosti maybutnih fahivtsiv fizichnogo vihovannya do vikoristannya zdorov'yazberezhuvalnih tehnologiy: teoretikometodichniy aspekt (Formation of readiness of future specialists of physical education to use healthpreserving technologies: theoretical and methodical aspect) (V.M. Lozoviy, Chernigiv, 2014) 
[51] R. Adams, S. Jeanrenaud, J. Bessant, D. Denyer, P. Overy, International Journal of Management Reviews 18, 180 (2016)

[52] S. Bruno, D.M. Tirca, Journal of Cleaner Production 208, 325 (2019)

[53] Z.F. Liotar, Sostoyaniye postmoderna (The state of the postmodern) (Aleteyya, St. Peterburg, 1979)

[54] G.O. Marsel, Tragicheskaya mudrost filosofii: izbrannyie rabotyi (The Tragic Wisdom of Philosophy: Selected Works) (Izd-vo gumanitar. lit.,
Moskva, 1995)

[55] Antichnaya filosofiya, Entsiklopedicheskiy slovar (Ancient Philosophy Encyclopedic, Dictionary) (Progress-Traditsiya, Moskva, 2008)

[56] A.I. Yarotskiy, Journal of Cleaner Production 25-28, 433 (1917)

[57] O. Klochko, V. Fedorets, O. Maliar, V. Hnatuyk, 166, 10033 (2020)

[58] V.D. Mendelevich, Psikhiatriya i psikhofarmakoterapiya 3, 57 (2017) 